\title{
Domesticación y modelos para la Neolitización de la Cuenca Mediterránea
}

\author{
Isabel RUBIO DE MIGUEL \\ Departamento de Prehistoria y Arqueología UAM
}

\section{Resumen}

Tradicionalmente, las investigaciones sobre la domesticación de animales y plantas y sobre la neolitización han discurrido paralelas, sin terminar de integrarse completamente. De hecho, el proceso señalado ha sido soslayado un tanto en investigaciones posteriores a los años setenta, sobre todo con la elaboración de modelos explicativos de la neolitización. Sin embargo, la domesticación es un proceso biológico con implicaciones sociales y un conocimiento adecuado de su aparición y desarrollo puede contribuir a corroborar o a desechar los referidos modelos. Por otro lado, los recientes estudios de ADN de las diversas especies parecen confirmar sugerencias emanadas de investigaciones más antiguas.

Palabras clave: domesticación, procesos, neolitización, modelos, Próximo Oriente, Mediterráneo.

\section{Summary}

Traditionally, research on animals and plants domestication and on Neolithic process went in parallel, without integrate completely one into another. In fact, this process was left aside, up to a point, in investigation later to the seventies, most of all, when explicative models of Neolithic were drawn up. But domestication is a biological process with social implications and an adequate knowledge of its emergence and development may contribute to corroborate or to discard the above-mentioned models. Recent DNA studies on species apparently confirm suggestions made in the context of previous research as well.

Keywords: domestication, processes, Neolithic, models, Near East, Mediterranean.

El proceso de domesticación de animales y plantas ha sido soslayado un tanto por las investigaciones en Prehistoria posteriores a los años setenta, aún siendo clave para los estudios sobre la neolitización. O mejor, podría decirse que los trabajos sobre el primero se han acometido de forma paralela a los de las segundas, sin terminar de integrarse del todo. No sería justo dejar de reconocer que, a día de hoy, especialistas en Paleobotánica y Arqueozoología trabajan en estrecha colaboración con prehistoriadores y arqueólogos y que, incluso, algunos de los referidos investigadores poseen la doble formación. Sin embargo, raramente se han tenido en cuenta las diversas particularidades del proceso de domesticación a la hora de elaborar modelos explicativos de la neolitización. En ese sentido, la aparición de animales y plantas domésticos suponía la identificación de grupos con economía productora, neolíticos, y particularmente para las áreas externas a los focos originarios, no se planteaba nada más, salvo la observación de las variaciones en el aprovechamiento de las distintas especies a lo largo del Neolítico. Casos paradigmáticos de desconexión han sido los modelos ofrecidos para explicar la neolitización del continente europeo (y por 
ende de la Península), dando por sentado que el proceso llegaba ya concluido desde el Próximo Oriente o, en el extremo opuesto, obras como la de D. Rindos (1990) sobre la aparición de la agricultura, quien proponía en 1984 un proceso coevolutivo (entre el comportamiento humano y el medio natural), que se iniciaría de forma casual, viéndose favorecidas algunas especies por acciones no intencionales del hombre y continuándose con una dependencia progresiva de las especies implicadas. Tal teoría ha recibido críticas entre otras razones precisamente por la descontextualización excesiva del proceso histórico del origen de la agricultura (Vicent en Hernando, 1994: 128).

\section{El estudio del proceso de domestica- CIÓN Y LA INVESTIGACIÓN DEL NEOLÍTICo}

En los últimos tiempos, una parte de los prehistoriadores y arqueólogos ha preferido centrar sus estudios en cuestiones de carácter global, como los sistemas económicos de las sociedades pretéritas y articular el debate en torno a las estrategias empleadas por estas para el aprovechamiento del medio o en otros aspectos, en lugar de hacerlo en torno al fenómeno biológico y sus vínculos culturales.

Sin embargo, podríamos decir que la domesticación es un proceso biológico con implicaciones sociales: animales y plantas domésticos pasan a depender del ser humano para su existencia, pero igualmente el hombre queda vinculado a las mismas, en grado variable, para su subsistencia. No deja de ser curioso que, a pesar de la desconexión antes señalada, las teorías iniciales sobre la aparición del Neolítico (hasta la irrupción de la Antropología cultural) hayan sido equivalentes a las del comienzo de la agricultura. De hecho, ya en el siglo XIX se inicia el estudio del origen de las plantas cultivadas por parte de distintos investigadores (A. de Candolle en 1884 y H.F. Roth en 1887) (Rubio, 1997: 13). Seguirán, a caballo entre el XIX y el XX, las investigaciones cruciales de N.I. Vavilov y otras más (E. Schiemann en 1932 y A.E. Watkins en 1933), ya en el siglo XX (Wright, 1971: 117). En todo caso, se tratará de estudios independientes que, no obstante y como no podía ser menos, tendrán su repercusión en la investigación del Neolítico. Recordemos que en la primera mitad de ese siglo se están generando también las teorías iniciales, clásicas, sobre el nacimiento del
Neolítico, focalizadas en el Próximo Oriente. En el Mediterráneo y en la Península Ibérica, será la explicación difusionista la que predomine.

La investigación de los años inmediatamente posteriores a la II Guerra Mundial realizada en el Próximo Oriente y el Egeo, que conducirá a la identificación de los grupos precerámicos, sitúa la economía de producción en primer plano, sirviendo a partir de entonces como elemento discriminante para identificar a los grupos neolíticos. La especulación sobre el origen de las especies involucradas de la cuenca mediterránea servirá para reforzar planteamientos difusionistas que, en el caso peninsular, contemplarán en algún momento la vía norteafricana (Rubio, 1997: 19).

En los años sesenta y setenta algunos de los enfoques introducen novedades. Por un lado, en los estudios paleobotánicos se inicia la experimentación (por Harlan, entre otros), al tiempo que se prosigue la investigación sobre el proceso de domesticación de las especies vegetales (es el caso de Helbaek) (Wright, 1971: 123-124). K. Flannery, en su teoría denominada "de las áreas marginales", valorará por primera vez (en 1969) el proceso biológico de la domesticación considerándolo fundamental, al afirmar que ciertas mutaciones en las especies silvestres potencialmente domesticables, que constituían uno de los ingredientes de la "revolución de amplio espectro" previa a la neolítica (Rubio, 1997: 20), ofrecieron una respuesta favorable lo mismo que determinados grupos humanos, posibilitando la domesticación.

Pero quizá lo más destacado será el interés de algunos investigadores británicos por las cuestiones de carácter económico y ambiental. J.D.G. Clark, considerado el fundador de la que se denominará Escuela paleoeconómica o paleoambiental de Cambridge, será un pionero en ese sentido (Trigger, 1992: 247-248). Su obra, ya clásica, Prehistoric Europe: its economic basis (1952) así lo demostraba y lo mismo el Proyecto sobre la historia antigua de la agricultura (British Academy Major Research Project on the Early History of Agriculture), desarrollado desde 1968 a 1976 y dirigido por E.S. Higgs y M.R. Jarman, componentes de dicha escuela. Según los planteamientos de dicho proyecto, los testimonios zoológicos y botánicos existentes indicaban la posibilidad de una agricultura antigua Postglaciar en el Viejo Mundo fuera de la supuesta zona originaria (el Próximo Oriente). La fecha de la domestica- 
ción de animales y plantas en el mundo demostraba la continuidad de un proceso desde los inicios del Postglaciar hasta hoy, debiendo buscarse los orígenes de la agricultura más atrás en el tiempo, si la domesticación se consideraba un cierto proceso de selección natural de la población humana y no el resultado de un oportunismo cultural (Barker, 1985: 8-9). Partiendo de tales premisas preferían estudiar el desarrollo de la agricultura no como una invención o serie de invenciones, diseñadas para controlar el entorno humano, sino como un proceso natural en continuo desarrollo de gran valor selectivo, en el que los ajustes a factores climáticos o ecológicos de otros tipos son visibles hasta la actualidad (Zvelebil, 1986: 13). Así, por ejemplo, se tomaban en consideración las distintas relaciones hombre animal, entre las que podía situarse la explotación intensiva de determinadas especies hoy consideradas salvajes como la gacela, el ciervo o el reno. Como consecuencia de todo ello, se produjo una valoración de los procesos locales en detrimento del foco originario próximo-oriental, y de los procesos protagonizados por las poblaciones mesolíticas. En ese sentido, la búsqueda de los referidos procesos locales no resultaba ni mucho menos descabellada, habida cuenta que estos, de existir, no tenían por qué reemplazar a la difusión o adquisición en general de especies, sino que podían ser simultáneos o darse en distintos tiempos, sobre todo para aquellas especies que tenían su agriotipo ampliamente extendido (lobo, uro, jabalí y algunas leguminosas en Europa).

Por otra parte, entre los años setenta y ochenta incluidos, Zeuner (1963) y Jarman (1976) sugerían distintos pasos en la domesticación de animales y Bökönyi (1969) y Davis (1987) suministraban indicadores destinados a identificar la domesticación y los procesos locales conducentes a ella para las especies animales, los cuales incluían cambios en la morfología, en la composición de la población faunística, así como otros indirectos.

En esos mismos años, el Neolítico peninsular contaba ya con datos sobre animales y plantas, que no sirvieron aún de base para estudios de carácter económico o como elementos discriminantes para identificar poblaciones neolíticas. El difusionismo seguía siendo la explicación preferida. En los años ochenta, tales estudios aumentan considerablemente, sirviendo las especies domésticas, supuestamente introducidas por colonos, para reafirmar la dualidad de poblacio- nes presuntamente existente en la Península. Por mi parte (Rubio, 1981 y otras publicaciones), la opción elegida será justamente la profundización en la economía de los grupos neolíticos. No obstante, en general, serán otros los elementos del equipo material los que ocupen el papel predominante, como en el caso de la industria lítica o la cerámica.

A partir de esos momentos, fuera y dentro de nuestras fronteras los modelos contemplan sobre todo cuestiones de carácter demográfico, las relaciones de tipo social, el sedentarismo o el almacenamiento, obviando los procesos de domesticación. Dichos modelos, sobradamente conocidos, se agrupan, con distintos matices, en difusionistas (colonización incluida) y aculturacionistas, que otorgan un papel menos pasivo a las poblaciones mesolíticas. En la Península, los modelos dual y de capilaridad vendrían a resumir estos enfoques. Los primeros defienden una llegada rápida y en bloque de los elementos característicos del Neolítico, las referidas especies entre ellos, vistas como una aportación de los colonos neolíticos, estudiando a continuación el papel que han jugado en las diversas áreas (predominio de los bóvidos en el NE, por ejemplo). El referido modelo dual ha experimentado modificaciones, al matizar sus planteamientos iniciales a causa de los nuevos descubrimientos. Modelos como el de capilaridad defienden, en cambio, que animales y plantas domésticos circularon por redes existentes entre cazadores-recolectores desde momentos previos al Neolítico, con un origen foráneo que habría que determinar (Próximo Oriente o Mediterráneo). Conviene recordar que no se contempla en este segundo la existencia de dos poblaciones distintas, ni se desprenden razones para pensar que todos los elementos neolíticos llegaran juntos, sino que su introducción dependería de los grupos que los adoptan, variando por tanto los tiempos y las causas. La consecuencia en cuanto a la investigación sobre las especies domésticas propiamente dichas son prácticamente las mismas en los dos modelos.

Es necesario insistir en que la investigación en Paleobotánica y Arqueozoología no se detiene, sino que evoluciona de forma independiente. Así por ejemplo y por lo que se refiere a las especies vegetales, se incide en la experimentación cultivando especies antiguas, como en el caso de los trabajos llevados a cabo por P. Anderson (Dir., 1992), surgen nuevos procedimientos de trabajo 
como los análisis de fitolitos y, más recientemente, se recurre a la Etnoarqueología para interpretar los restos y determinar procesos agrícolas (Peña, 1993 y después).

En un momento dado, se introducen explicaciones de la neolitización basadas en el mundo simbólico (las de I. Hodder y J. Cauvin, que no son las únicas) (Hodder, 1990 y Cauvin, 1994) que, por razones obvias, no se ocupan de las cuestiones citadas.

Los procedimientos de estudio han evolucionado de forma espectacular y en el momento presente es posible llevar a cabo interpretaciones impensables dos décadas atrás, aunque los datos sigan siendo un tanto desiguales. Sin embargo, artículos recientemente publicados permiten volver sobre ciertos conceptos y planteamientos, demostrando que algunos enfoques anteriores no eran erróneos y que los procedimientos más o menos rudimentarios empleados permitían entrever, al menos, la complejidad de los procesos. Que tales procedimientos son cruciales en la investigación de estos los demuestran los estudios de ADN a lo que nos referiremos, así como la utilización de herramientas ya aplicadas en su momento (estudio de la demografía de la población faunística) para responder ahora a nuevos interrogantes.

\section{Datos antiguos y nuevos del Próximo ORIENTE}

Ante todo cabe señalar que, precisamente en función de las revisiones de los más antiguos testimonios existentes sobre la domesticación de animales y plantas, diversos autores (Aurenche y Kozlowski, 1999: 55-56 y Kuijt, 2000: 3-13, entre otros) proponen la reconsideración de las denominaciones habitualmente empleadas en las secuencias neolíticas que en su opinión tienen un carácter sobre todo cronológico a día de hoy, prefiriéndose el empleo de los periodos establecidos en el ASPRO (Atlas des sites du Proche Orient).

La publicación de datos recientes (Willcox et alii, 2008: 42) sobre hallazgos del Natufiense (Periodo 1, 12000-10300 calBC) evidencia la existencia de algunas particularidades del valle del Éufrates, en relación con la agricultura predoméstica: reducción de frecuencias de las semillas comúnmente recolectadas (Polygonus, Scirpus, Stipa, etc.), aumento de los agriotipos de las especies "fundadoras" (escaña y escanda menor, cebada y lentejas), crecimiento del tamaño de los granos e introducción de nuevos cultivos como cebada, seguida de escaña (1 grano) y escanda menor. Estas especies serán dominantes más tarde, pero su aparición fuera del área de distribución natural indica su cultivo. M.A. Zeder (1999) propuso un proceso similar para todo el Próximo Oriente, que implicaba el consumo de recursos estacionales y estáticos postpleistocénicos, complementado con la caza de especies interesadas en las mismas plantas. Al restringirse la movilidad, la caza selectiva llevó al control de las especies y a su domesticación, desarrollándose paralelamente técnicas de almacenamiento. Fue esta una fase de experimentación que sólo dejó huellas en la composición de la población faunística (sexo y edad), pero hizo a los grupos humanos más receptivos a las especies domésticas, cuando estas se introdujeron.

En la actualidad, dejando de lado el criterio tradicional, ya desechado, de la reducción de tamaño en los animales del Próximo Oriente, las particularidades observadas en los restos de fauna se atribuyen más bien a prácticas de grupos ganaderos, por contraste con la explotación efectuada por los cazadores-recolectores. En el NE de Irán y en el SE de Anatolia (hacia el 12000 calBP), parecen entreverse rasgos relacionados con la gestión de la demografía de las manadas locales, que supuestamente reflejan una estrategia de caza determinada (Zeder, 2008: 3). En el SE de Anatolia (10500 calBP), se documenta este fenómeno sobre ovejas, además de la presencia de cabras foráneas, manipuladas igualmente, en torno al 10200 calBP, en este caso. Estos hechos indican que ambas especies fueron sometidas a domesticación, de forma independiente posiblemente y en diversos momentos (Zeder, 2008: 3). En Ganj Dareh (Irán, 9900 calBP), los cambios en la morfología de las cabras aparecen 500 o 1000 años después de un aumento demográfico y de su traslado a zonas más cálidas, como una respuesta a diversas presiones selectivas. El cerdo parece haberse domesticado por primera vez en el SE de Anatolia (10500-10000 calBP), pero los que presentan alteraciones morfológicas no se encuentran en el sur de Levante y en las tierras bajas de Irán hasta aproximadamente $8500-8000$ calBP. La vaca, por su parte, se domesticó inicialmente en el alto Éufrates hacia 11000 y 10000 calBP. De 
nuevo, cerdo y vaca con cambios morfológicos no aparecen en Asia central hasta después del 8500 calBP (Zeder, 2008: 3). En conclusión, la domesticación de animales en esa región se puede ver como el nacimiento de un periodo de interacción humana prolongada con los antepasados de las principales especies en el Creciente Fértil. Las estrategias de caza intentaron desarrollar una manipulación activa, maximizando la disponibilidad local de los ungulados salvajes y llegando a la domesticación en los cuatro casos entre aproximadamente el 9500 y el 9000 calBP (Zeder, 2008: 4).

El precerámico (Periodos 2 a 4, 10300-6900 calBC), identificado por K. Kenyon en Jericó y dividido en PPNA y PPNB, debe ser replanteado en este momento, fundamentalmente porque las domesticaciones defendidas para el PPNA (10000-8800 calBC) se han rechazado después de las pertinentes revisiones. Los restos de trigo de Jericó se reducen a sólo 4 granos y los de Tell Aswad IA fueron agrupados de diferentes niveles. El aumento de los pólenes de cereales de la fase III de Mureybet no permite determinar la domesticidad de estos y la de los testimonios de cebada de Netiv Hagdud ha sido negada después por el propio paleobotánico. Los hallazgos más antiguos de ovejas y cabras tampoco eran demasiado seguros, ya que en ocasiones su pertenencia o no a la forma doméstica se había hecho con arreglo a criterios que podríamos calificar de indirectos y de menos fiables por sí solos. Se trataría, en el caso de las primeras, de los restos de Zawi ChemiShanidar (Irak), fechados entre el 9000 y el 8900 bc. Otros testimonios fueron los de Ali Kosh (7000 bc), Çayönü y Jarmo con fechas similares, así como algunos más del PPNB de Levante. Más recientemente, sin embargo, la revisión de los datos de los yacimientos iraquíes ha hecho que se consideren como bastante improbables de cualquier modo (Helmer, 1991: 90-93).

Sin embargo, estos hallazgos podrían muy bien sugerir la existencia de esa protoagricultura y de ese control de las especies animales que se defiende en la actualidad. A día de hoy, puede decirse que la Revolución Neolítica en general, por lo que se refiere al inicio de prácticas conducentes a una economía de producción, se habría operado en las sociedades de cazadores-recolectores, con anterioridad al reconocimiento en la documentación de grupos neolíticos en el sentido tradicional. De hecho, esta agricultura predoméstica se evidencia en la presencia de plantas adventicias y de cascabillos de los granos. De ahí que sea posible encontrarnos en presencia de esas fases "silenciosas", arqueológicamente hablando, en las que, sin embargo, se están operando cambios en las especies e integrando las prácticas agrícolas en una economía de amplio espectro. En resumen, aunque el concepto de precerámico en su acepción tradicional no tendría sentido para el PPNA, no podría negarse tampoco la existencia de cambios que igualmente se perciben en otros ámbitos. Por otro lado, según los datos que poseemos en la actualidad, se producen domesticaciones locales de las distintas especies a lo largo del PPNA y del PPNB por lo menos, de forma paralela o sucesiva a importaciones de otras a partir de focos más o menos lejanos de la misma región próximo-oriental.

El verdadero Neolítico, entendido como una etapa en la que se constata en los restos arqueológicos, con seguridad, el cultivo y la domesticación de animales, apareció en la segunda mitad del Periodo 3 (PPNB medio, 8000 calBC), en todo caso con características variables. A partir de ahí, el nuevo modo de vida se impone, hallándose ya extendido por todo el Próximo Oriente al final de esta etapa, sin que se abandone la caza y la recolección de todos modos. Nuevos datos indican que ya a finales del PPNB próximo-oriental (7000-6200 calBC) aparecen también los primeros indicios de selección voluntaria de los animales (disminución aún menor de la talla o cuernos torneados en el caso de las cabras, tal como se documentan en Tell Aswad, por ejemplo). Puede suponerse que otras transformaciones morfológicas, como la mejora de la capacidad lechera de la oveja y de la vaca habrían tenido lugar entonces (Vigne, 2005: 94). Sin embargo, desde el punto de vista arqueológico resulta complicado determinar tales selecciones.

Según señala J.D. Vigne (2005: 99-100), la gestión de la leche puede determinarse a través del contenido de recipientes, pero también de la composición de la población faunística. La selección de la oveja para estos fines se documenta, según sus datos (Vigne, 2005: 102-103), en yacimientos europeos, sólo unos siglos después de la introducción de la especie en el litoral del 
Mediodía francés y la de la vaca se sugiere para el yacimiento de Torre Sabea (Apulia) (Neolítico antiguo, finales del $\mathrm{VII}^{\circ}$ y todo el $\mathrm{VI}^{\circ}$ milenio) (Vigne, 2005: 106). En resumen, la explotación de la oveja/cabra para la leche pudo darse en los inicios del VIII ${ }^{\circ}$ milenio en el Próximo Oriente y en la segunda mitad del $\mathrm{VI}^{\circ}$ en el Mediterráneo occidental y, en el caso de la vaca, desde los inicios del $\mathrm{VI}^{\circ}$ milenio en el sur de Italia y en el $\mathrm{V}^{\mathrm{o}}$ $I^{\mathrm{o}}$ en la cuenca de París (Vigne, 2005: 107). Por esta razón, la leche no puede considerarse ya una producción secundaria, sino un factor potencialmente principal de la domesticación de rumiantes en el Próximo Oriente y quizá del incremento demográfico humano neolítico, siempre en opinión de J.D. Vigne (2005: 109).

Los datos genéticos corroboran lo dicho hasta ahora, confirmando también que Ovis orientalis y Capra aegagrus son los agriotipos de oveja y cabra y determinándose igualmente al menos de 4 a 6 linajes genéticos o haplotipos de la primera (Zeder, 2008: 4). La cabra ha sido el primer herbívoro en ser domesticado (10000 bp). De hecho, según los autores antes citados, ha podido ser la primera "despensa andante" y provocar la domesticación subsiguiente de las especies euroasiáticas que proporcionaron el grueso de las proteínas animales consumidas (MacHugh y Bradley, 2001: 5382). Los estudios llevados a cabo por Luikart y otros investigadores sobre el ADN mitocondrial de la misma (en MacHugh y Bradley, 2001: 53835384), indican que la cabra tiene tres raíces matrilineales (A, B y C), a diferencia del resto de los animales a los que hacemos referencia en estas páginas. Ninguno de los ejemplares de Capra aegagrus estudiados aparecen en estas ramas, frente a lo observado en otros momentos (MacHugh y Bradley, 2001: 5383). Estudiando el citocroma B, se llegó a la conclusión de que hubo al menos tres capturas geográfica y temporalmente separadas de la cabra bezoar durante la formación de las poblaciones más antiguamente domesticadas, lo que no puede ser explicado por una sola domesticación, habida cuenta del elevado número de hembras que intervendrían en este proceso (MacHugh y Bradley, 2001: 5383). Los tres linajes antes citados se expanden en distinto momento: el A, el más diverso y predominante en todo el mundo, inició su expansión con la domesticación hace 10000 años, el B hace 2000, locali- zándose en el sur de Asia, y el C hace 6000, detectándose en un pequeño número de individuos domésticos en Europa y en un solo animal en Mongolia. Ello indica que los dos últimos derivan de expansiones secundarias y terciarias que siguen a la primera (MacHugh y Bradley, 2001: 5383-5384). Sin embargo, un muestreo más amplio puede alterar este panorama. Se ha determinado igualmente que la localización geográfica tiene escasa relevancia en el tipo de ADN mitocondrial, lo que sugiere que la cabra fue una especie altamente móvil, empleada como elemento pequeño y transportable en el comercio (MacHugh y Bradley, 2001: 5384).

En cuanto a la vaca, su agriotipo es el uro, con lo que en principio la posibilidad de domesticación en la propia Europa y, en general, fuera del Próximo Oriente no parecía descabellada. Sin embargo, merced a los estudios de ADN, se ha rechazado la vinculación de la vaca doméstica europea con el uro de este continente. Cabe suponer que esta afirmación deba ser corroborada con datos más numerosos. Se han determinado igualmente los linajes genéticos o haplotipos de esta especie: 5 , de los cuales 3 o 4 se originaron posiblemente en el Creciente Fértil. Recientemente, R. Bollongino y J. Burger (2007) han dado a conocer el resultado de estudios de ADN, practicados sobre restos de bóvidos de yacimientos europeos y próximo-orientales, correspondientes al Neolítico y, algunos de ellos, al Mesolítico y Bronce (Bollongino y Burger, 2007: 166). Este estudio indica, por una parte, la exclusión de una domesticación independiente de bóvidos en Europa: la distancia molecular entre uros y vacas es tan grande, incluso en el Neolítico antiguo, que no puede defenderse un proceso local. Por otro, demuestra que no hubo un centro de domesticación independiente en Hungría como defendía Bökönyi ni tampoco cruces entre la vaca importada y el uro europeo (Bollongino y Burger, 2007: 185). Este último aspecto, no obstante, solo podrá conocerse con seguridad con el análisis del cromosoma Y. Habida cuenta que el uro europeo no es el progenitor de la vaca doméstica, se propone como área de posible domesticación Anatolia y el Próximo Oriente en general (Bollongino y Burger, 2007: 184-185), donde la diversidad genética es hoy más elevada. 
En cuanto al cerdo, tradicionalmente se había venido defendiendo la posible existencia de varios centros de domesticación: el sureste de Europa, el sureste de Asia y la región póntica. Datos recientes, procedentes asimismo de análisis genéticos indican que, efectivamente, los cerdos europeos podrían descender de la domesticación del jabalí local (Vigne, 2005: 91). Los linajes genéticos o haplotipos de esta especie se han determinado igualmente. Al menos 3 o 4 de ellos proceden del Próximo Oriente. Con todo y en general, no se puede asegurar que los haplotipos sean "spatially and temporally discrete domestication events" (Zeder, 2008: 4), en los que diferentes poblaciones de animales fueron domesticados independientemente unos de otros.

También por lo que se refiere a las plantas se trata de un proceso bastante prolongado. Los datos de múltiples áreas apuntan en esa dirección, dándose durante el mismo una manipulación humana de plantas genéticamente silvestres pero cultivadas, algunas de las cuales llegaron a experimentar cambios morfológicos. Esta situación se remonta al 12000 calBP, detectándose los cambios en 10500 calBP. En todo caso, las economías agrícolas basadas en unas y otras especies no cristalizan del todo en el Próximo Oriente hasta aproximadamente 9500-9000 años calBP (Zeder, 2008: 4).

\section{Datos antiguos $Y$ Nuevos Del MediterRáneo}

Las especies domésticas halladas en el Mediterráneo y por tanto en la Península Ibérica con cronología más antigua son el perro, la oveja, la cabra, la vaca y el cerdo y las vegetales: trigo, cebada y leguminosas (habas, guisantes, lentejas, almortas o guijos y arvejas o yeros).

M.A. Zeder (2008) constataba a partir de estudios de ADN en los nuevos yacimientos excavados en Chipre (10500-9000 calBP) la manipulación demográfica de ovicaprinos, vaca y cerdo y la caza de gamo y zorro, introducidos desde el Creciente Fértil. Algo similar sucede con escaña y escanda menor, lentejas y cebada que, silvestre, es endémica de la isla (Zeder, 2008: 5). Se atestigua así el fenómeno ya documentado en el Próximo Oriente de manipulación previa (y "exportación" de la misma, por lo que se ve) a los cambios mor- fológicos de determinadas especies, introducidas desde esta región.

Recientes análisis genéticos de ADN mitocondrial confirman al lobo como antecesor del perro, al menos con dos ancestros diferentes y una antigüedad de unos 135000 años. Sin embargo, estos datos plantean problemas al existir la posibilidad de hibridación con lobos actuales. Las tasas de mutación, por otra parte, no son estables. Se confirma así también que su antepasado silvestre estaría muy repartido. En este caso concreto, parece que los procesos locales se dan por supuesto, aunque es algo que resta por esclarecer.

En un momento dado, ciertos hallazgos suscitaron el debate y plantearon la existencia de procesos locales en el Mediterráneo. Los tempranos casos de supuesta domesticación de oveja (niveles mesolíticos de Châteauneuf-les-Martigues, restos de Gramari, Gazel, Rouffignac y Cap Ragnon) abrieron la polémica. Ducos y también Poulain opinaban que dicha especie (una oveja salvaje de pequeña talla) pudo estar ya domesticada en los niveles mesolíticos del $\mathrm{VII}^{\circ}$ milenio y a partir del 6000 bc (en Guilaine, 1976). Ahora se puede afirmar con seguridad que la oveja ha sido introducida doméstica a partir del Próximo Oriente o de lugares más cercanos que, en último extremo, la habrían importado de esa región. Pero además, se sabe que la oveja de Châteauneuf es intrusiva, lo mismo que los ovicaprinos de Dourgne y Gazel, sin contar con que la cabra de Gazel es ibex. En otros casos, parece haber habido una confusión con Rupicapra o Capra pyrenaica. Así pues queda claro que ni la oveja ni la cabra parecen haber tenido su agriotipo en el Mediterráneo, por lo que hay que pensar que estas especies hubieron de ser forzosamente importadas, independientemente de cuál haya sido el procedimiento para su adquisición.

Los haplotipos de cabra doméstica (A y C) llegan al sur de Francia hacia el 7300 calBP, desde el Próximo Oriente, en un paquete único. Estos dos linajes se encuentran igualmente en rebaños modernos de cabra de Portugal, en los que asimismo se detectan tres linajes de ovejas, incluidos los hallados con anterioridad únicamente en el Próximo Oriente y Asia. Oveja y cabra muestran un grado mucho más alto de diversidad genética de lo que cabría esperarse en la periferia occidental de la expansión de estos animales. Esta diver- 
sidad se atribuye a múltiples introducciones de caprinos en la Península, llegados no sólo por colonización marítima desde Francia e Italia (a juicio de Zeder), sino por subsiguientes introducciones desde África y de otras áreas de Europa (Zeder, 2008: 7).

La genética señala también múltiples introducciones de la vaca. El haplotipo T3 que domina dicha especie antigua y moderna europea parece haber tenido una rápida expansión por la cuenca mediterránea. El ADN moderno indica que T y T2 de la vaca estaban incluidos en movimientos migratorios hacia los Balcanes y Europa central. Por su parte T1, dominante en los toros modernos del norte de África, procedería de la domesticación de otro toro del haplogrupo T en el Próximo Oriente, que se difundió después por el norte de África por intercambio y migración humana. La aparición desigual del T1 en el toro moderno de la Península, Sicilia e Italia central y los Balcanes sugiere la llegada por el sur de Europa y el norte de África a través de múltiples puntos de entrada. Es posible igualmente que T1 viajara a través de los Dardanelos al este de Europa.

En cuanto al cerdo, la investigación de Larsson y otros autores publicada en 2005 (en Zeder, 2008: 7) ha mostrado que los modernos europeos no tienen rasgos de antepasados del Próximo Oriente, sino que están relacionados más estrechamente con el jabalí europeo. Estudios de ADN de los restos arqueológicos indican una dispersión desde esta región a través de Europa entre 7500 y 5000 calBC. Poco después de esta dispersión inicial, el cerdo próximo-oriental es reemplazado por otros domésticos de ascendiente materno europeo, incluso en el Próximo Oriente. Así, la domesticación indígena del jabalí europeo parece haberse producido en varias ocasiones, con dos linajes principales, indicativos de los acontecimientos separados de domesticación de este y otro linaje adicional, restringido a Italia y Cerdeña (Zeder, 2008: 7). Los autores antes citados (Larsson et alii en Zeder, 2008: 11) sugieren que la domesticación del jabalí europeo fue posible después de la introducción del cerdo doméstico desde el Próximo Oriente, con lo que realmente se trata de un caso de transferencia tecnológica más que de una domesticación independiente auténtica. Quedaría pues por concluir esta en el caso de los jabalíes indígenas.
La presencia de algunas leguminosas (guisante, garbanzo, haba, arveja, almorta y lenteja) (Pisum sp., Cicer aretinus, Vicia sp., Vicia ervilia, Lathyrus cicera y Lens sp. sculenta Moench., respectivamente) con formas cercanas a las cultivadas, en yacimientos franceses como la Cueva de l'Abeurador primero (Vaquer, 1980), y la Baume de Fontbrégua o Abri de la Poujade después, en niveles mesolíticos, llevó a plantear en su momento la autoctonía de su origen. En opinión de R. Buxó (1997), las especies halladas en l'Abeurador (8500-6500 bc) serían oriundas de la región y habrían supuesto una domesticación sin ulteriores consecuencia. Marinval (1991: 88) sostuvo que podrían tratarse de aportaciones no antrópicas, si bien afirmaba que la abundancia de granos y sus grandes dimensiones en l'Abeurador y Fontbrégua, suponían una recolección intensiva que habría llevado a una preagricultura a lo largo del VIII ${ }^{\circ}$ milenio, por la importancia que estas y otras especies habían tenido en la alimentación de estos grupos mesolíticos, pero también por la eliminación de plantas competidoras.

El mismo hecho parece darse en la Grotta dell'Uzzo (Sicilia), en la que se han encontrado pequeñas cantidades de leguminosas y frutos silvestres. Durante un tiempo se defendió que la Cueva Franchthi (Grecia) mostraría igualmente la potencialidad de la recolección de plantas y la posibilidad de una protoagricultura (cebada, avena y lentejas silvestres), pero veinte años más tarde, Hansen (en Perlès, 2001: 30-40) se desdijo de estas afirmaciones. Por otro lado, las lentejas silvestres halladas eran Lens nigricans o Lens ervoides, mientras que el agriotipo de la cultivada es Lens orientalis (Lens culinaris subsp. orientalis), según han demostrado los estudios genéticos. Sin embargo, la lenteja cultivada es difícil de distinguir de la silvestre y la cuestión de la determinación de la domesticidad de las leguminosas en general puede plantear problemas. De hecho, algunas de ella pueden tener su agriotipo en el Mediterráneo (Vicia faba narbonensis y Lathyrus cicera, aunque con dudas) (Zohary y Hopf, 1994: 114). En definitiva, según algunos autores, lo estudios genéticos reducen la aparición de los trigos primarios (escaña y escanda menor) y de ciertas leguminosas (garbanzo, haba, arveja y posiblemente guisante) al ámbito del Próximo Oriente (Perlès, 2001: 40). Sin embargo, parece evidenciarse la necesidad de datos más numerosos para establecer con seguridad el origen. 
Ahora bien, ¿por qué mecanismos han sido introducidas las especies foráneas? Los modelos antes comentados dejan claro que, o bien han constituido una aportación de colonos llegados del Mediterráneo (Próximo Oriente incluido), o bien circularon como elementos de intercambio por redes establecidas entre las poblaciones existentes en la región. J. Chapman (1991), por ejemplo, defendía la existencia de un conjunto de tales redes de reproducción que estimularon el intercambio generalizado durante el Mesolítico final-Neolítico antiguo (8000-5500 calBC), introduciéndose a través de ellas las nuevas especies como alimento o como ganado, lo que les otorgaría nuevo valor y podría haber contribuido a una dispersión posterior (Chapman, 1991: 127). En opinión de Chapman (1991: 127-128), la domesticación es común a cazadores-recolectores y agricultores, constituyendo la única distinción la tendencia entre estos últimos al sedentarismo y, por tanto, a un incremento de los campamentos base.

Abundando en este modelo, Ch. Perlès (2001: 60) defiende, de modo similar, la existencia de redes de intercambio amplias, que podrían haber incluido la obsidiana y habrían representado un importante incentivo para la difusión de la agricultura. En este caso concreto, Ch. Perlès (2001: 46) sugiere una adopción selectiva por intercambio de estos elementos. Por lo tanto, J. Chapman y Ch. Perlès ofrecen una visión fluida y sin rupturas de la transición, abogando por la presencia de redes de intercambio y no por la llegada de gentes (o no siempre), así como por una selección de elementos (las nuevas especies entre ellos), producida en el ámbito de los mecanismos antes aludidos. En ese contexto, la continuidad será la característica en la cuenca mediterránea, con adquisición o adopción paulatina de los distintos elementos. Así, por ejemplo, en la Cueva Franchthi, ya cita$\mathrm{da}$, se documenta una continuidad entre el Mesolítico y el Neolítico, pasando de una economía de amplio espectro (caza de ciervo, pesca y recolección de plantas) a una fase agrícola con caprinos domésticos, cebada y trigo en un primer momento, y vacas, cerdos y cerámica en otro posterior (Chapman, 1991: 128). Aquí, al igual que se está comprobando en otras partes de Europa, se pone de manifiesto la interacción entre mesolíti$\cos$ y neolíticos durante una breve etapa (Neolítico inicial), mientras que el cambio mayor se produce después de esta última. Esta misma complejidad ha sido planteada desde otra óptica por Ch. Jeunesse (2003) para la aparición de la agricultura en Europa central. Lamentablemente no podemos detenernos en este caso concreto, no exento de debate.

Lo mismo parece documentarse en el Mediterráneo central. En ciertos yacimientos (Grotta dell'Uzzo, Grotta de Latronico 3, Coppa Nevigata y Torre Sabea) se documenta también un importante componente mesolítico en las primeras fases neolíticas (Tusa, 1991: 116). Para S. Tusa (1991: 118), es indudable que ha habido un fenómeno de transferencia de conocimientos tecnológicos y de especies desde los Balcanes. Sin embargo, las poblaciones receptoras no van a experimentar una mera aculturación, sino que procurarán diversificar su base de subsistencia. Esta tendencia supone para dicho investigador la existencia entre el $\mathrm{VII}^{\circ}$ y el $\mathrm{VI}^{\circ}$ milenios de un proceso de tendencia autónoma al estadio productivo, por lo que no será improbable la domesticación de algunas especies que tuvieran su agriotipo en la zona (Tusa, 1991: 118). En este contexto, se introduce lo nuevo, sin trauma alguno para poblaciones con un fenómeno de adaptación óptima, dándose una fuerte autonomía selectiva de los grupos receptores.

Otros investigadores comparten también estas ideas. K. Mazurié, quien se decantaba por el modelo de difusión arrítmica defendido por $\mathrm{J}$. Guilaine para la neolitización europea (Mazurié, 2007: 221-232), subrayaba la variedad de culturas, difusiones rápidas y frenos que adoptaron algunas de ellas por diversas causas. En su opinión, la primera neolitización europea no fue el resultado de un proceso único, regular y progresivo. La dinámica de tal proceso evolucionó en función de las reacciones del sustrato mesolítico. La introducción de novedades no se relacionó sólo con la colonización y la expansión demográfica, sino que fue fruto de la difusión y la aculturación, que nunca supusieron un aporte de población importante (Mazurié, 2007: 225). Únicamente en las dos primeras etapas de la neolitización, entre el 6800 y el 6100 y entre el 6100 y el 5800 calBC, se puede hablar de aportes demográficos, construyendo después Europa sus propios esquemas culturales sobre una base de población que desde el punto de vista genético es posiblemente autócto- 
na (Mazurié, 2007: 226). K. Mazurié (2007: 119) se pregunta además si no habremos subestimado, a falta de testimonios arqueológicos, el papel de los grupos mesolíticos, ya que en occidente no se reconoce el sistema cultural próximo-oriental, salvo en lo referente a la economía de producción. Por ello, sería preciso salvar la dicotomía colonización-autoctonía.

Cauwe y otros investigadores (2007: 39) afirman que la documentación actual hace inconcebible un Neolítico europeo, salido exclusivamente de las corrientes migratorias, lo que es particularmente visible en la periferia del continente, donde las sociedades depredadoras han desarrollado modos de vida originales. La generalización de las economías de producción se acompaña de interacciones culturales, evidenciándose el peso del sustrato mesolítico en la continuidad de las industrias líticas en la generalidad del continente, en este caso. Así mismo, estos autores indican que, desde el $\mathrm{VII}^{\circ}$ milenio calBC, el modo de vida neolítico se difunde al Mediterráneo central y occidental (Cauwe et alii, 2007: 98), sin un reemplazo generalizado de la población y sin que todos los elementos sean transmitidos o asimilados al mismo tiempo. En ese sentido, se recuerda (Cauwe et alii, 2007: 25-26) que aunque L. Cavalli-Sforza concluyó, basándose en el ADN nuclear, que la gran mayoría de la población actual europea descendía en línea directa de los primeros agricultores que colonizaron Europa, la escuela de Bryan Sykes ha postulado, según el ADN mitocondrial que el $95 \%$ a $97 \%$ de los europeos están ligados a grupos provenientes de África, establecidos en Europa a inicios del Holoceno. Únicamente el 3\% o 4\% tendría su origen en los primeros agricultores del Próximo Oriente. Por lo que parece que, tampoco en este caso, los datos genéticos avalarían la colonización.

En cuanto al Mediterráneo, Cauwe y otros autores (2007: 110) señalan que los grupos cardiales muestran que la caza juega un papel importante al lado del cultivo de cereales y de la domesticación de ovejas y cabras. Los mencionados investigadores opinan que se asiste a un aporte de población y a una incorporación de elementos culturales por parte de los mesolíticos. La selección de los colonos y las tradiciones de los mesolíticos actuaron como filtros, contribuyendo a la elaboración de una nueva cultura. La documentación arqueológica sugiere también que no se transmite todo el conjunto neolítico o no siempre, sino que existe una selección.

Pero aun aceptando la colonización, parece atestiguarse en el este del Mediterráneo que la transición ha sido más compleja de lo supuesto y la intervención de los grupos mesolíticos más importante. Para M.A. Zeder, la supuesta expansión de población no sugiere la tendencia lenta, sostenida y acompasada predicha por el modelo de ola de avance (Zeder, 2008: 7). Por otro, lado, aunque ovicaprinos, vaca y plantas pioneras no se domesticaron de forma independiente, los datos de los cerdos sí lo indican en distintos momentos y en subpoblaciones geográficamente separadas. Los estudios genéticos de centeno y avena modernos señalan que también tuvieron un antepasado europeo y no próximo-oriental.

\section{A MOdo de Conclusión}

En resumen, los nuevos procedimientos de análisis proporcionan al investigador herramientas para examinar todo el proceso de la domesticación, no sólo sus impactos morfológicos (si suceden), que únicamente aparecen cuando éste se halla sobradamente en marcha. En el Creciente Fértil, se están detectando signos de "ingeniería" que buscan e impulsan la producción de plantas y que son capaces de documentar la manipulación de la estructura del rebaño para promover un rendimiento más seguro y predecible de productos animales. Está abierta la cuestión de cuánto hay que llevar hacia atrás esta gestión de recursos y hasta dónde estuvo extendida en el Próximo Oriente (Zeder, 2008: 10). Así pues, cabe señalar que, si bien estos procedimientos han desechado la existencia de domesticación en el PPNA, negándose por este motivo su condición de precerámico tradicional, por otro lado confirman que las prácticas que desembocan en la domesticación están ya en marcha, incluso desde el Tardiglaciar. Por ello, de alguna manera, en el PPNA se estarán produciendo igualmente cambios trascendentales. Dentro del Próximo Oriente, el fenómeno tampoco es uniforme: procesos, adquisiciones y préstamos se han dado en las diversas regiones, lo mismo que seguramente fracasos (¿caso de la gacela?).

El ADN de las especies ratifica los agriotipos tradicionalmente defendidos e indica el origen próximo-oriental, sin duda alguna, de oveja, 
cabra, vaca y trigo. Habrán de corroborar también posibles procesos locales vinculados al lobo, asî como a la cebada y a algunas leguminosas. Igualmente, han confirmado la domesticación del cerdo, en varias ocasiones y fuera del Próximo Oriente. Esta especie parece haber circulado también en la dirección contraria, constatándose en general múltiples introducciones de caprinos en la Península, a partir del Próximo Oriente, Europa y África (a falta de profundizar en los estudios, especialmente de esta última zona), así como de la vaca. Todo lo cual ofrece una imagen demasiado compleja como para defender un proceso de neolitización unilineal y restringido en el tiempo.

Las precisiones hechas en la actualidad sobre el estudio de la composición de la población faunística han permitido sugerir la gestión de la leche en el caso de los ovicaprinos y la vaca (en Europa y presumiblemente también en el Próximo Oriente), alimento que pasaría a ser ahora uno de los factores principales para la domesticación. La "Revolución de los productos secundarios" de Sherratt, más tardía, deberá ser revisada también, algo que se podía sospechar a partir de ciertos testimonios indirectos.

La llegada a Chipre de algunas especies manipuladas, 2000 años antes de la cristalización de las economías agrícolas en el continente, indica que la comprensión de la aparición de la domesticación animal y el nacimiento de la agricultura están incompletos. También se ha demostrado que la expansión por el Mediterráneo fue mucho más compleja y poligenética de los que mostraban los primeros modelos. En distintas áreas, en diferente grado, el proceso implicó elementos de difusión demográfica, adopción local y domesticación independiente. En opinión de Zeder (2008: 10), la colonización marítima de la cuenca mediterránea implicó múltiples migraciones independientes, aunque lo relacionado con ella: contexto cultural, causas, rutas, tiempos, debe ser investigado. Parece urgente, entonces, profundizar en la investigación de las estrategias puestas en práctica por las poblaciones mesolíticas, ya que ahí parece estar la clave. Pero también convendría insistir en los estudios de ADN de las poblaciones humanas para esclarecer definitivamente el alcance de la supuesta circulación de gentes por el Mediterráneo, si la hubo, y su papel en la colonización de las áreas limítrofes con el Próximo Oriente y en las islas.
Según Melinda A. Zeder (2008: 11), la costa norte de África parece un área prometedora para futuras investigaciones, así como la llegada y transición en las islas. Cabe recordar que recientemente, en la Península, se están defendiendo relaciones con el norte de África para explicar el Neolítico andaluz. Sin embargo, por el momento, no puede proponerse claramente este vínculo porque el Neolítico magrebí aún presenta muchas lagunas y determinados datos están apuntando al área sahariana. Para la autora citada (Zeder, 2008: 11), cabría investigar domesticaciones de especies silvestres europeas, la extinción de faunas endémicas de las islas y el papel de los humanos en la configuración de los entornos postneolíticos.

En conclusión, los mecanismos de adquisición de las especies fueron varios, rompiendo con la imagen axial de la difusión del Neolítico. Igualmente, a día de hoy, la existencia de procesos locales no resulta descabellada, ya que si por una parte los estudios de ADN han zanjado determinadas polémicas en ese sentido, por otro han sugerido posibilidades alternativas al respecto. El caso de Chipre muestra cómo ha podido darse igualmente la introducción de especies en vías de transformación. A ese respecto, sería lógico pensar que tales especies, silvestres o no, adquiridas por el mecanismo que fuera, experimentarían un proceso de adaptación a nuevos territorios, lo mismo que el grupo humano a nuevos recursos. Por lo tanto, ninguno de los modelos explicativos que defienden la neolitización mediterránea mediante una colonización, rápida generalmente, se ajusta claramente a la transición, si tenemos en cuenta además de los datos anteriores, los provenientes de otros restos materiales de los que no es posible ocuparnos aquí (la cerámica, por ejemplo).

Podemos afirmar entonces que los grupos mesolíticos finales mediterráneos (europeos, en general) no son entes pasivos, sino que se hallan perfectamente adaptados al ámbito mediterráneo, no tan distinto al próximo-oriental por otro lado, que van diversificando su economía para reproducir su modo de vida, seguramente satisfactorio. En ese contexto, pueden plantearse posibles domesticaciones locales o, al menos, una tendencia a la economía de producción, experimentación incluida, pero también un horizonte (Neolítico inicial, según Jeunesse), en ocasiones claramente 
separado del Neolítico antiguo, en el que se adquieren determinados elementos: especies y/o cerámica, generalmente, con importantes aportaciones de las tradiciones mesolíticas. En todo caso, se obtiene ahora la impresión de la primacía de las primeras sobre la segunda. El Neolítico antiguo ofrece ya todo el conjunto de elementos que tradicionalmente caracteriza a los hallazgos de grupos productores, aunque no siempre su presencia en los yacimientos peninsulares y europeos se atestigua en bloque (podría hablarse de un modelo de mosaico). En la Península, sin embargo, hay excepciones: es el caso de Portugal, así como de ciertas áreas de la región cantábrica y NO, donde la economía de producción no se evidencia de forma tan nítida. En cuanto al mecanismo de adquisición de las especies y de otros elementos, una buena parte de los investigadores se decanta hoy por la existencia de redes de subsistencia e intercambio, ya establecidas entre las poblaciones mesolíticas, que serán las protagonistas del cambio. Así, desde el punto de vista de la economía se corrobora la explicación ofrecida en modelos alternativos a los de colonización, basados sobre todo en otro tipo de restos materiales, sin que se documente una situación de ruptura.

La neolitización del Mediterráneo y, por tanto, la peninsular es un fenómeno complejo, integrado por múltiples componentes, que una interpretación sencilla no puede explicar satisfactoriamente. Ya en momentos anteriores, podían observarse ciertas situaciones que ahora se evidencian con mayor claridad, a mi juicio. Cierto que la economía de las poblaciones mesolíticas había sido escasamente estudiada, lo mismo que la ordenación del territorio, cosas ambas fundamentales para defender determinadas conexiones o barreras entre unos y otros grupos, en el supuesto de que hubiera llegada de gentes (algo que personalmente no he defendido nunca). La búsqueda de procesos locales que, en su momento, podían encuadrarse en los planteamientos de la Escuela de Cambridge, no implicaban la existencia de focos neolitizadores por doquier. Ya entonces, al abordar cuestiones como la de la domesticación (y estos extremos se han confirmado en estos momentos), en cuanto fenómeno biológico y cultural, se afirmaba que no eran procesos unilineales y que podían repetirse o producirse con una cierta variabilidad. En una palabra, en cada lugar en el que se adquieren las especies señaladas se inicia un proceso de adaptación (al medio y al grupo humano y viceversa), que ya no dependerá de selecciones y estrategias introducidas desde el exterior. Pero recordemos igualmente que coexistirían distintos tipos de economía, como también afirmábamos en su momento (Rubio, 1981: 1413). Además no sólo los cazadores-recolectores participarán en el proceso, sino también los propios grupos neolíticos: de nuevo los procesos locales parecen atraer el interés de los especialistas y nada impide, como se ha sugerido en el caso del cerdo, un "contagio" de tipo técnico o una experimentación que permita ampliar el abanico de recursos.

En una palabra, la neolitización tanto en el foco originario como en el Mediterráneo constituye un proceso con múltiples intervenciones del que restan por investigar numerosos aspectos (entre ellos las posibilidades de domesticación de especies silvestres o testimonios de acercamiento entre especies animales y el hombre, la caza especializada una de ellas). Produce, en todo caso a día de hoy, una cierta seguridad comprobar que desde los estudios llevados a cabo sobre especies animales y vegetales y desde los que se basan en el equipo material de las poblaciones mesolíticas y neolíticas se llega a parecidas conclusiones. De esa manera, de algún modo tiende a cerrarse el círculo abierto en los años sesenta y setenta sobre la complejidad de los procesos de domesticación y de neolitización.

\section{BibLIOGRAFía:}

ANDERSON, P. (Dir.) (1992): Préhistoire de l'agriculture. CNRS.

AURENCHE, O. y KOZLOWSKI, S.K. (1999): La naissance du Néolithique au Proche Orient. París.

BARKER, G. (1985): Prehistoric farming in Europe. Cambridge.

BÖKÖNYI, S. (1969): "Archaeological problems and methods of recognizing animal domestication". UCKO, P.J. y DIMBLEBY, G.W., The domestication and exploitation of plants and animals, 219299. Chicago.

BOLLONGINO, R. y BURGER, J. (2007): "Neolithic cattle domestications as seen from ancient DND". WHITTLE, A. y CUMMINGS, V. (Eds.), Going over. The Mesolithic-Neolithic Transition in North-West Europe, 165-187. Oxford. 
BUXÓ, R. (1997): Arqueología de las plantas. Barcelona.

CAUVIN, J. (1994): Naissance des divinités. Naissance de l'agriculture. París.

CAUWE, N. et alii (2007): Le Néolithique en Europe. París.

CLARK, J.D.G. (1955): L'Europe préhistorique. Les fondements de son economie. París.

CHAPMAN, J. (1991): “Els orígens de l'agricultura al sud-est d'Europa". Cota Zero 7, 126-135.

DAVIS, S.J.M. (1987): The archaeology of animals. Londres.

GUILAINE, J. (1976): Premiers bergers et paysans de l'Occident méditerranéen. París.

HELMER, D. (1999): La domestication des animaux par les hommes préhistoriques.

HERNANDO, A. (1994): "El proceso de neolitización, perspectivas teóricas para el estudio del Neolítico". Zephyrus XLVI, 123-142.

HIGGS, E.S. y JARMAN, M.R. (1972): “The origins of animal and plant husbandry". HIGGS, E.S. (Ed.), Papers in Economic Prehistory, 3-26. Cambridge.

HODDER, I. (1990): The domestication of Europe. Londres.

JARMAN, M.R. (1972): "European deer economies and the advent of the Neolithic". HIGGS, E.S. (Ed.), Papers in Economic Prehistory, 125-147. Cambridge.

JARMAN, M.R. (1976): “Animal husbandry. The early stages". HIGGS, E.S. (Dir.), origine de l'élevage et de la domestication, Colloque $X X, I X^{o}$ Congrès de la U.I.S.P.P.(13-18, septembre, Niza), 22-50.

JEUNESSE, Ch. (2003): "Néolithique “initial”, néolithique ancient et néolithisation dans l'espace centre-européen: une vision rénovée", Revue de l'Alsace 129, 97-116.

KUIJT, I. (2000): Life in Neolithic Farming Communities. KUIJT, I. (Ed.), Life in Neolithic Farming Communities, Social organization, Identity and Differentiation, 3-13. Nueva York.

MAcHUGH， D.E. y BRADLEY, D.G. (2001): "Livestock genetic origins: Goats buck the trend". Proceedings of the National Academy of Sciences of the United States of America 98 (10), 53825384.
MARINVAL, P. (1991): “L'economia de subsistencia a França durant el Mesolitic i el Neolitic: les aportacions de la carpología". Cota Zero 7, 88-95.

MAZURIÉ, K. (2007): El origen del neolítico en Europa. Agricultores, cazadores y pastores. Barcelona.

PEÑA, L. (1993): "Los modelos etnográficos en Arqueobotánica: los cereales vestidos”, I Jornadas Internacionales sobre Tecnología agraria tradicional, 21-29. Salamanca.

REED, Ch.A. (1984): The beginning of animal domestication. MASON, I.L. (Ed.), Evolution and domesticated animals, 1-11, Londres-Nueva York.

RINDOS, D. (1990): Los orígenes de la agricultura. Barcelona.

RUBIO, I. (1981): Aspectos socio-económicos del neolítico peninsular. Tesis doctoral inédita. Universidad Autónoma de Madrid.

RUBIO, I. (1997): "El paradigma difusionista y la neolitización de la Península Ibérica: una explicación recurrente", CUPAUAM 24, 9-58.

TRIGGER, B. (1992): Historia del pensamiento arqueológico. Barcelona.

TUSA, S. (1991): “Consideracions sobre el procès d'adquisició neolítica a la Italia meridional i a la Sicília”, Cota Zero 7, 115-125.

VAQUER, J. (1980): “De la cueillette à l'agriculture: la Grotte de l'Abeurador". Les premiers paysans, Dossiers de l'Archaéologie 44, 18-19.

VIGNE, J.D. (2005): “Maîtrise et usages de l'élevage et des animaux domestiques au Néolithique: quelques illustrations au Proche Orient et en Europe". GUILAINE, J. (Dir.), Populations néolithiques et environnements, 87-115. París.

WILLCOX, G.H. et alii (2008): "Changes in the use of cereal on the Euphrates sites between 11,500 and 7,800 B.C. cal.”. BUXÓ, R. y MOLIST, M. (Dir.), MENMED. From the adoption of Agriculture to the Current Landscape: long term interaction between Men and Environment in the Near East Mediterranean Basin, Monografíes 9. Museu d'Arqueologia de Catalunya, 41-44. Barcelona.

WRIGHT, G.A. (1971): “ Origins of food production in Southwestern Asia: a survey of ideas", Current Anthropology 12.4-5, 447-475.

ZEDER, M.A. (1999): “Animal domestication in the Zagros: a review of past and current research", Paléorient 25.2, 11-25. 
ZEDER, M.A. (2008): “Domestication and early agriculture in the Mediterranean basin: origins, diffusion and impact", Proceedings of the National Academy of Sciences of the United States of America 105 (33), 11597-11604.

ZEUNER, F.G. (1963): A History and Domesticated Animals. Londres.
ZOHARY, D y HOPF, M. (1994): Domestications of plants in the Old World. Oxford.

ZVELEBIL, M. (1999): Mesolithic prelude and neolithic revolution. ZVELEBIL, M. (Ed.), Hunters in transition, 5-15. Cambridge. 